Military Technical College

Kobry El-Kobbah, Cairo, Egypt

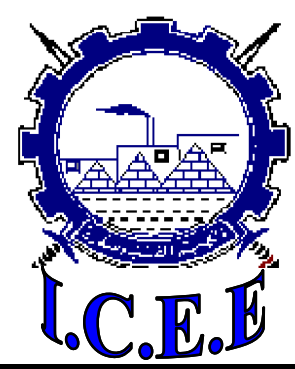

CT-4 $5^{\text {th }}$ International Conference on

Chemical \& Environmental Engineering

\title{
POTENTIAL USE OF AQUEOUS SOLUTION OF TARTARZINE DYE AS LOW-DOSE DOSIMETER FOR GAMMA RADIATION
}

Ahmed F. Tawfik, Ahmad A. Baraka, Mohammad M. Gobara and Ahmed M. Omar*

\begin{abstract}
In this study, Tartarzine aqueous solution was investigated as a simple low-dose dosimeter in the range of 20-500 Gy for the high ionizing radiation, gamma ray. Gradual bleaching of Tartarzine solution was observed with dose by measuring the absorbance of Tartarzine-solutions at specified wavelength, $\lambda_{\max }=430 \mathrm{~nm}$. Tartarzine concentration $\left(10^{-4}, 5 \times 10^{-4}\right.$ and $\left.10^{-3} \mathrm{M}\right)$ and solution-initial $\mathrm{pH}$ value $(5,7$ and 9) were considered as factors affecting degree of bleaching. It was found that Tartarzinesolution color was diminished gradually with selected dose range. The rate of bleaching increases with the increase of solution-initial $\mathrm{pH}$. Increase of Tartarzineconcentration causes widening of range to which solution is susceptible. The postirradiated effect (24 hours) was found to cause more bleaching. The sensitivity of Tartarzine solution is not regular with the Tartarzine-concentration and regular with $\mathrm{pH}$.
\end{abstract}

\section{Keywords}

Gamma radiation, Degradation, sensitivity, Tartarzine, Dosimeter

\footnotetext{
* Egyptian Armed Forces
} 


\section{Introduction}

The gamma-induced color bleaching of many organic dyes has been widely investigated. Most of the reported experimental works have been performed in aqueous aerated acidic or alkaline solutions. The decrease of absorbance with irradiation, bleaching, suggests that it can be use as a chemical dosimeter [1-4].

It has been reported that the decolorization could be explained in terms of interaction of radicals $\mathrm{H}^{\cdot}$ and ${ }^{\circ} \mathrm{OH}$ with the dyes in de-aerated aqueous solutions and in terms of $\mathrm{HO}_{2} / \mathrm{O}_{2}{ }^{-}$ and ${ }^{\circ} \mathrm{OH}$ interactions in aerated aqueous solutions. $\mathrm{H}^{\circ}$ is generally associated with the reversible reductive decolorization and the radicals ${ }^{\circ} \mathrm{OH}$ and $\mathrm{HO}_{2}{ }^{\circ} / \mathrm{O}_{2}^{-}$are considered to be the cause of the reversible oxidative decolorization [5-6]

Radiation effect at dose range up to $120 \mathrm{kGy}$ on some dyes in non aqueous solvents such as methyl orange, Congo red, phenol red in acetone and ethanol and dimethylformamide was studied [7]. The bleaching of some dyes with different concentrations in non-aqueous solutions indicates that these dyes are promising as a chemical dosimeters.

Moreover, aqueous solution of methyl red as a dosimeter for gamma radiation at dose range up to $6 \mathrm{KGy}$ was studied. Bleaching of its alkaline and acidic solutions containing different amounts of ethanol showed its possibility for using these dye as a chemical dosimeters [8]. Tartarzine (known as E102 or FDC Yellow 5) is a synthetic lemon yellow azo-dye used as a food coloring. Its structure is shown in Figure 1. It is found in many food stuff, soft drinks, instant puddings, flavored chips, cake mixes, custard powder, soups, sauces, ice cream, candy...etc. It is also found in some pharmaceutical products and cosmetics such as soaps, hair products, moisturizers, crayons, stamp dyes, vitamins, antacids, medicinal capsules and certain prescription drugs [9-12]. It is an available and not expensive material.

In the present work, solutions of Tartarazine were investigated as gamma radiation dosimeter. Tartarzine with different concentrations and $\mathrm{pH}$ values were subjected to gamma radiation in the dose range between (20-500 Gy) and then the absorbance of tartarazine dye in the UV-Vis range is determined.

\section{Experimental}

Tartarzine (from local source, Kamena Co.) and bi-distilled water are used to prepare different solutions of concentrations; $10^{-4}, 5 \times 10^{-4}$ and $10^{-3} \mathrm{M}$. The solutions are then, each, placed in $40 \mathrm{ml}$ plastic vial. The vials are then introduced into gamma cell (Gamma Chamber 5000 / India, dose rate $=2.1 \mathrm{kGy} / \mathrm{hr}$ ) to be exposed to a steady state radiolysis. The dose range studied was $20-500 \mathrm{~Gy}$. Prior to irradiation for each vial, the $\mathrm{pH}$ value was adjusted using $0.1 \mathrm{M} \mathrm{HCl}$ and $0.1 \mathrm{M} \mathrm{NaOH}$ aqueous solutions using Hanna pH-211.pH meter.

Tartarzine degradation was detected by measuring the absorbance of irradiated samples using Shimadzu UV-160 spectrophotometer at $\lambda_{\max }=430 \mathrm{~nm}$. All measurements were carried out at ambient temperature using quartz cells with $1 \mathrm{~cm}$ optical path length. The $\mathrm{pH}$ value for each sample was also determined after gamma irradiation. Figure 2 showed the absorbance spectrum of tartarazine in UV-Vis. range with a peak at $430 \mathrm{~nm}$ which is used to determine the concentration of tartarazine for all samples. 
Two set of measurements were performed, the first one immediately after irradiation (within about 10 minutes) and the second one, same samples, on a longer term (after 24 hours). The long term samples were kept after irradiation under normal laboratory conditions in dark.

\section{Results and discussion}

\subsection{Degradation reactions}

The azo compounds, such as tartarazine, are usually intensely sively colored because the diazenediyl linkage $(-\mathrm{N}=\mathrm{N}-)$ brings the two aromatic rings into conjugation. This gives an extended system of delocalization of $\pi$ electrons and allows absorption of light in the visible region [13]. When a reproducible relationship between the absorbance of dye solution and the irradiation dose is observed, the use of this as chemical dosimeter may be proposed. Gamma irradiation causes gradual color bleaching of organic dyes, hence gives a chance for such application. For non de-aerated solution, the bleaching may be due to oxidative decolorization reaction with $-\mathrm{N}=\mathrm{N}$ - group (the chromophore moiety in Tartarzine compound) by $\mathrm{HO}_{2}{ }_{2} / \mathrm{O}_{2}{ }^{-}$and ${ }^{\circ} \mathrm{OH}$ produced by gamma irradiation [7]. Figure 2 shows an example of such degradation of Tartarzine (initial concentration $=5 \times 10^{-4} \mathrm{M}, \mathrm{pH}=9$ and doses from 0 to 500 Gy).

The exact mechanism of bleaching needs an intensive investigation of intermediates during reaction and pulse radiolysis technique is recommended which was not available for this study. However, a preliminary suggestion may be given based on that the azo bonds were broken by the oxidation processes [6].

\subsection{Degradation of tartarzine (measurement 10 minutes after irradiation)}

Figure 3, 4 and 5 shows a gradual decrease of Tartarzine solution absorbance of different concentrations for different $\mathrm{pH}$ values. The samples of initial concentration $10^{-4} \mathrm{M}$ can only withstand dose up to $100 \mathrm{~Gy}$. After this dose, the Tartarzine residual concentration was hardly detected by the spectrophotometer. The other two higher concentrations $\left(5 \times 10^{-4}\right.$ and $\left.10^{-3} \mathrm{M}\right)$ can survive up to $500 \mathrm{~Gy}$. The response to dose with respect to $\mathrm{pH}$ is similar for all concentrations studied. It can be observed that as initial $\mathrm{pH}$ increases, bleaching increases. I.e., degradation oxidative processes are more efficient as solution becomes more alkaline. However, the before- irradiation and after-irradiation $\mathrm{pH}$ values for each sample have not significantly changed. This means that $\mathrm{pH}$ parameter is a catalytic one and does not involve in the oxidative reaction. This important phenomenon will pearly be studied latter.

Linear regressions of data give the equations that represent the linear fitted absorbance response to dose (Abs. against dose). It is summarized in Table 1. To select the best conditions at which this dosimeter properly work, the correlation factor $(r)$ was regarded. By revising the different values of $r$, it can be concluded that the sample of concentration of $10^{-3}$ $\mathrm{M}$ with $\mathrm{pH} 5$ is the preferred one to apply. Although this $\mathrm{pH}$ condition is less sensitive to radiation compared to the other two $\mathrm{pH}$ conditions, its stability with doses (higher $r$ ) still prefer it to apply especially as the Abs. response is not that much different from the other two $\mathrm{pH}$ conditions.

The sensitivity of solutions (sensitivity: the absorbance change, $\Delta$ Abs., per unit dose, Gy) is an important factor to discuss. For each sample, the sensitivity is the slope of its equation, Table 1. Change of sensitivity with respect to change of concentration and $\mathrm{pH}$ are given in Figures 9 and 10 respectively. From Figure 9, the change of sensitivity is not regular which direct the user to carefully study the concentration to be used as an independent case, i.e. each 
concentration has its behavior towards irradiation. On the contrary, from Figure 10, the change of sensitivity is regular and this suggests that solution behavior can be predicted for different $\mathrm{pH}$ values other than studied ones. It is worthy to mention, in general, that sensitivity represents the rate of degradation with respect to dose and this rate increases with $\mathrm{pH}$ increase. This suggests a faster degradation at ultimately higher $\mathrm{pH}$ values (12-14) which enable user to apply this dosimeter for very low gamma doses.

\subsection{Post irradiation degradation (measurement 24 hours after irradiation)}

Determination of degradation of after a lag time is a stability test. It is performed to find to what degree the solution change with time that may affect the measurements. The degradation of samples after 24 hours is shown in Figures 6, 7 and 8. In general, all post-irradiation samples show more bleaching compared to after-irradiation. Sample prepared at $\mathrm{pH} 9$, for all concentrations studied, still shows more bleaching than those prepared at $\mathrm{pH} 7$ and 5 and this observation is similar to after-irradiation measurements. For concentrations $5 \times 10^{-4} \mathrm{M}$ and $10^{-3} \mathrm{M}$ which subjected to doses up to $500 \mathrm{~Gy}$, the former shows more degradation.

Again, linear regressions of data give the equations representing absorbance against dose. It is summarized in Table 1. By revising the different values of $r$, the best sample to apply is that of concentration of $10^{-4} \mathrm{M}$ with $\mathrm{pH} 5$. The sensitivities are the slopes of equations, Table 1 . Change of sensitivity with respect to change of concentration and $\mathrm{pH}$ are given in Figures 11 and 12 respectively.

From figure 11, the change of sensitivity is not regular (reasonably as in the previous case) and careful selection of concentration has to be considered. From Figure 12, the change of sensitivity is regular and indicates a good prediction of degradation as $\mathrm{pH}$ changes.

Percentages difference, PD\%, of Abs. between samples of "directly after irradiation" and "post irradiation, 24 hours" are given in Table 2. From table, no consistency or a trend can be observed. This suggests careful dealing with "post irradiation" data with respect to "directly after irradiation". However, in general an extra degradation of 5-6\%, on average can be considered for the 24 hours lag effect.

\section{Conclusion}

Tartarzine aqueous solution with different concentrations $\left(10^{-4}, 5 \times 10^{-4}\right.$ and $\left.10^{-3} \mathrm{M}\right)$ at different $\mathrm{pH}$ values $(5,7$ and 9) were subjected to gamma irradiation. The results showed that tartarazine degradated linearly, to some extant, with increasing gamma dose. In general, as solution $\mathrm{pH}$ increases, the rate of bleaching increases. Moreover the $\mathrm{pH}$ values did not change after irradiation due to degradation of Tartarzine and consequently the stability of this solution can be suggested. Increase of Tartarzine-concentration causes more span of dose within which tartarzine solution is susceptible to gamma radiation. The post-irradiation effect (24 hours) causes 5-6\% more bleaching on average. The change of sensitivity of tartarzine solution is regular with $\mathrm{pH}$ values but Tartarzine-concentration does not show the same regularity. According to sensitivity study, faster degradation of Tartarzine (i.e. with low doses) is probable at high $\mathrm{pH}$ values (e.g. in 12-14 range). Tartarazine is a promising dosimeter when concentration is considered with care. 


\section{References}

[1] C.M. Foldvary, L. Wojnarovits, "The effect of high-energy radiation on aqueous solution of Acid Red 1 textile dye" Radiation Physics and Chemistry 76 (2007) 14851488

[2] A.S. Ozen , V. Aviyente , R.A. Klein "Modeling the oxidative degradation of azo dyes: a density functional theory study" Journal of Physical Chemistry Vol 17 (2003) 48984907.

[3] W.L. McLaughlin, "Radiation chemistry of anionic diazo dyes in Cellophane films applications for high-dose dosimetry" Radiation Physics and Chemistry vol 67 (2003) 561-567.

[4] M.A. Rauf, S. Salman Ashraf. "Radiation induced degradation of dyes An overview" Journal of Hazardous Materials 166 (2009) 6-16

[5] Hinda Lachheb ,Eric Puzenat, Ammar Houas, Mohamed Ksibi, Elimame Elaloui, Chantal Guillard, Jean-Marie Herrmann "Photocatalytic degradation of various types of dyes (Alizarin S, Crocein Orange G, Methyl Red, Congo Red, Methylene Blue) in water by UV-irradiated titania"Applied Catalysis B: Environmental vol 39 (2002) 75-90

[6] Zaki ajji "usability of aqueous solutions of methyl red as high-dose dosimeter for gamma radiation" Radiation Measurements 41 (2006) 438-442

[7] M.F. Barakata, K. El-Salamawya , M. El-Bannaa, M. Abdel-Hamida,A, Abdel-Rehim Taha "Radiation effects on some dyes in non-aqueous solvents and in some polymeric films" Radiation Physics and Chemistry 61 (2001) 129-13

[8] J.H. Ramirez, C.A. Costa, L.M. Madeira, "Experimental design to optimize the degradation of the synthetic dye Orange II using Fenton's reagent" Catalysis Today (2005) 68-76.

[9] J.H. Sun, S.P. Sun, G.L.Wang, L.P. Qiao "Degradation of azo dye Amido black 10B in aqueous solution by Fenton oxidation process" Dyes and Pigments vol 74 (2007) 647652.

[10] R. Liu, H.M. Chiu, C.S. Shiau, R.Y.L. Yeh, Y.T. Hung, "Degradation and sludge production of textile dyes by Fenton and photo-Fenton processes" Dyes and Pigments vol 73 (2007) 1-6.

[11] J. He, W. Ma, J. He, J. Zhao, J.C. Yu, "Photooxidation of azo dye in aqueous dispersions of $\mathrm{H}_{2} \mathrm{O}_{2} / \mathrm{FeOOH} "$ Applied Catalysis B Environmental vol 39 (2002) 211 220.

[12] C.C. Liu, Y.H. Hsieh, P.F. Lai, C.H. Li, C.L. Kao, "Photodegradation treatment of azo dye wastewater by UV/TiO2 process" Dyes and Pigments vol 68 (2006) 191-195

[13] T.W.G Solomons,.., Organic Chemistry, 1996, $6^{\text {th }}$ Edition, New York, John Wiley and Sons, 


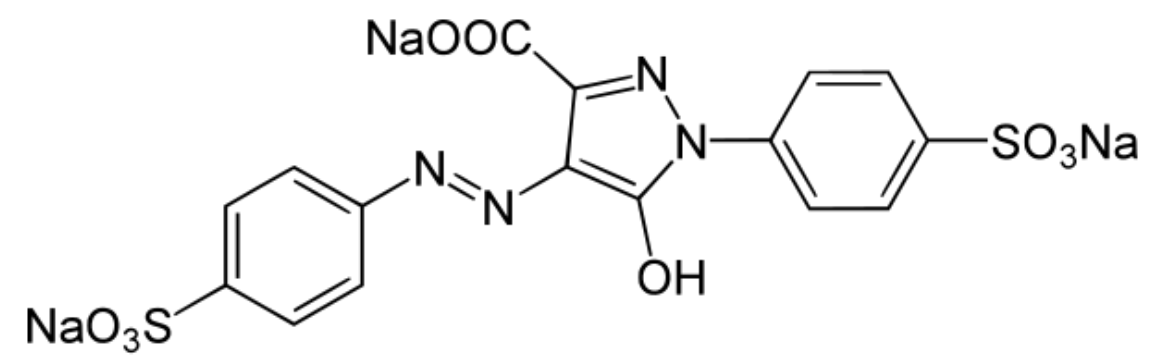

Figure 1: Chemical structure of Tartarzine

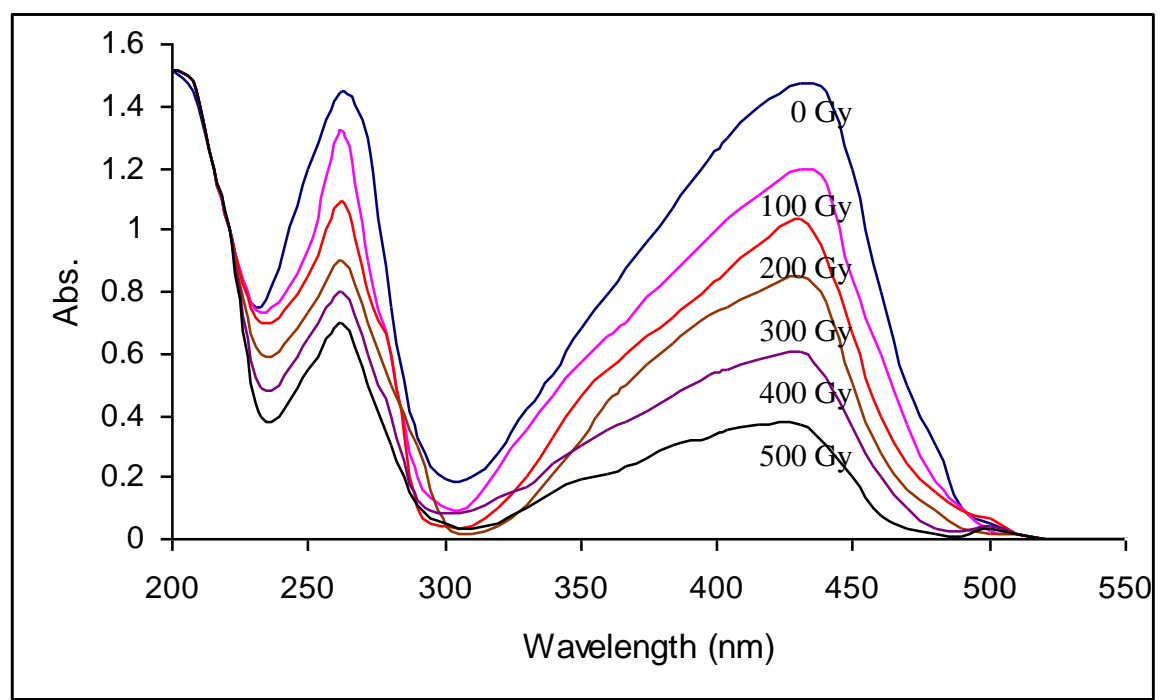

Figure 2: UV-Vis Tartarzine absorbance spectra for different doses (0 to $500 \mathrm{~Gy}$ ), concentration $=5 \times 10^{-4} \mathrm{M}$ and $\mathrm{pH}=9$. 


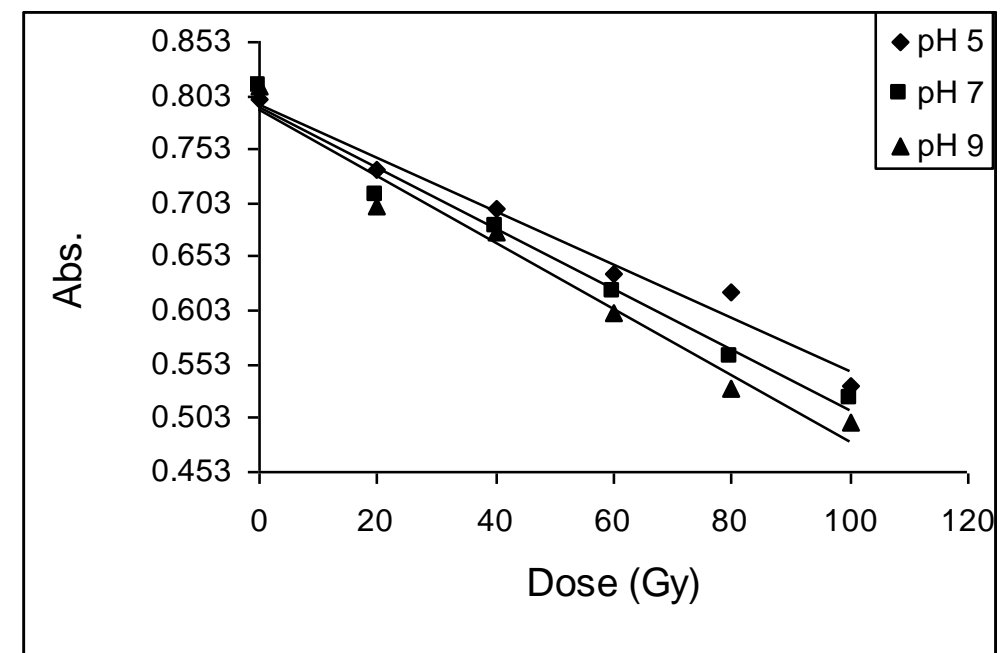

Figure 3: Tartarzine of concentration $10^{-4} \mathrm{M}$ at $\mathrm{pH}(5,7$ and 9).

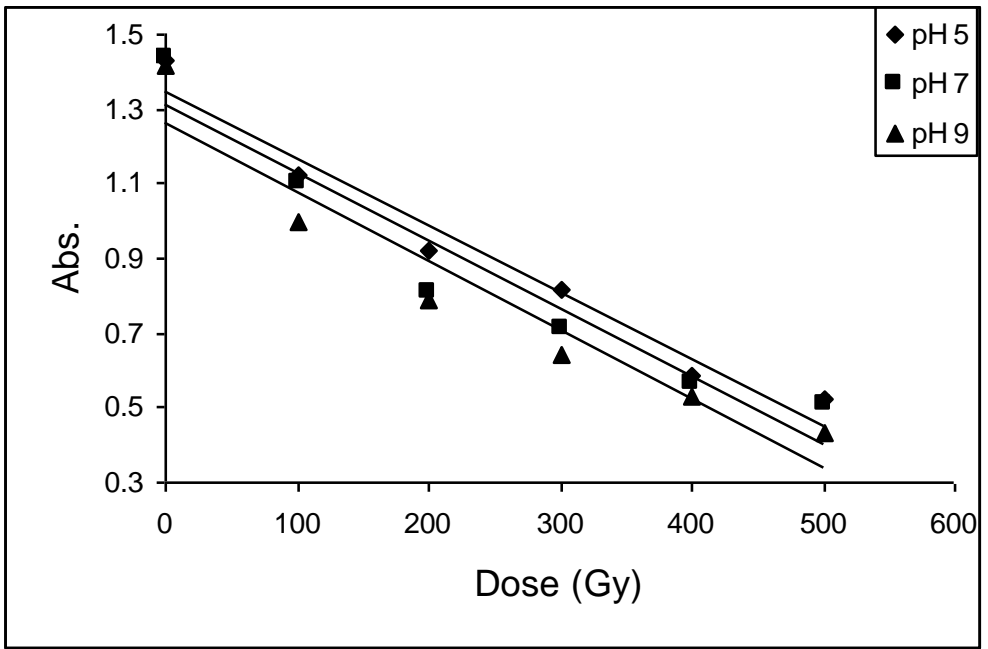

Figure 4: Tartarzine of concentration $5 \times 10^{-4} \mathrm{M}$ at $\mathrm{pH}(5,7$ and 9).

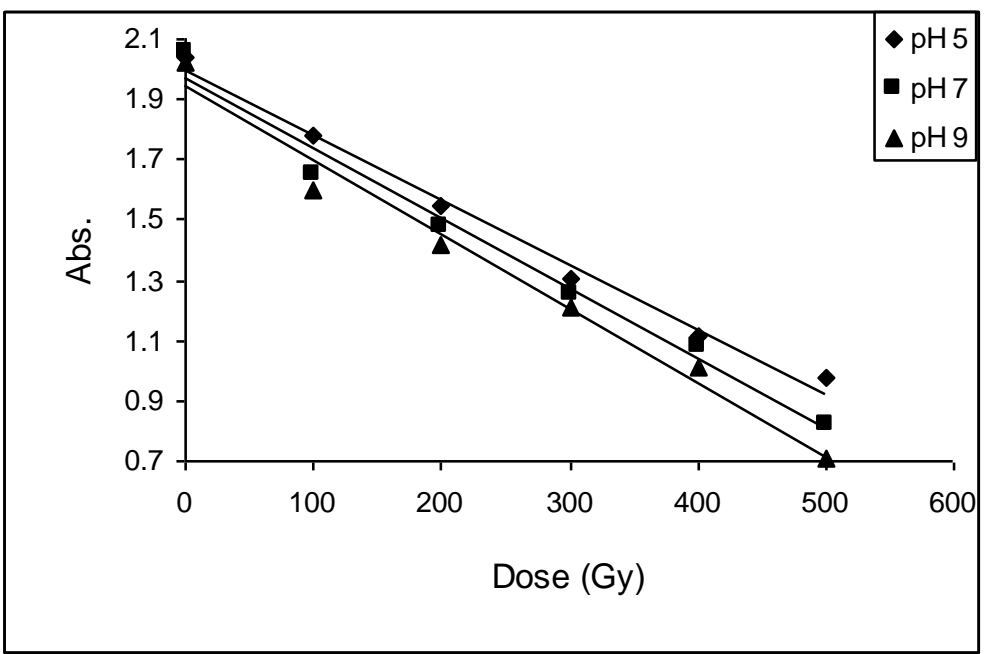

Figure 5: Tartarzine of concentration $10^{-3} \mathrm{M}$ at $\mathrm{pH}(5,7$ and 9). 


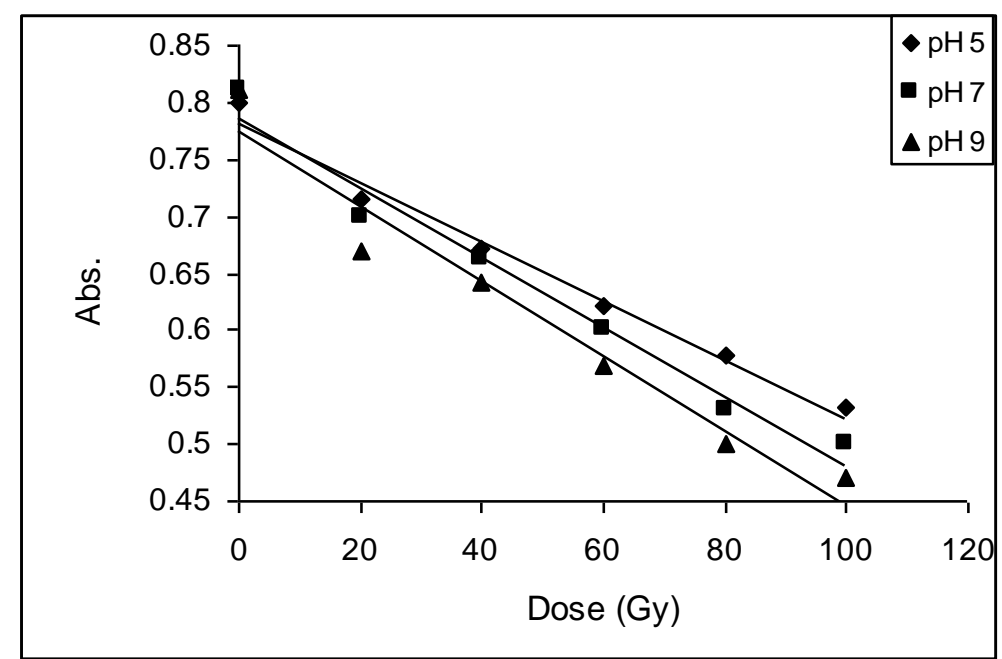

Figure 6: shows that Tartarzine of concentration $10^{-4} \mathrm{M}$ is more bleached after 24 hours of primary irradiation especially at $\mathrm{pH} 9$

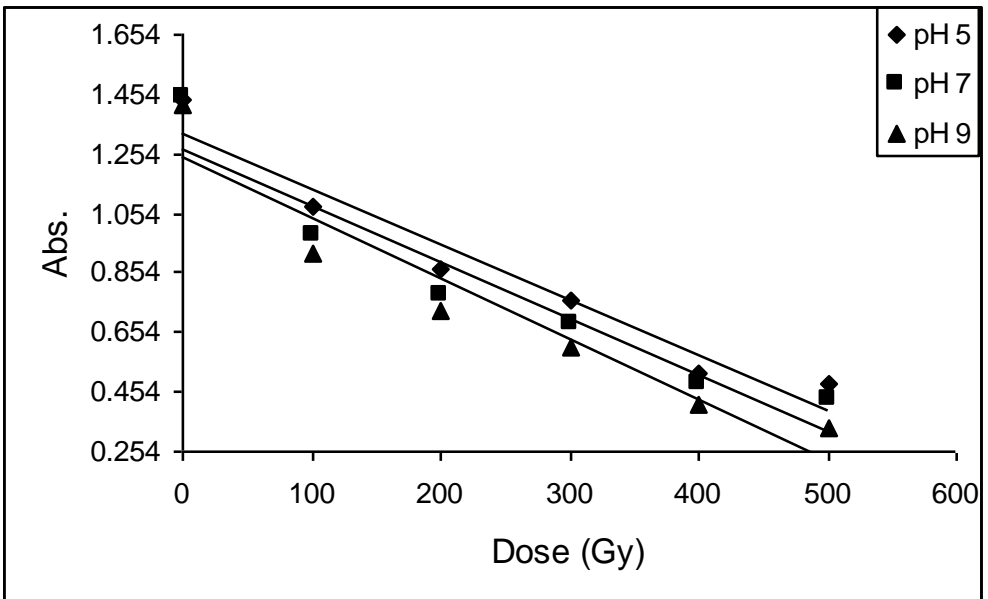

Figure 7: shows that Tartarzine of concentration $5 \times 10^{-4} \mathrm{M}$ is more bleached after 24 hours of primary irradiation especially at $\mathrm{pH} 9$

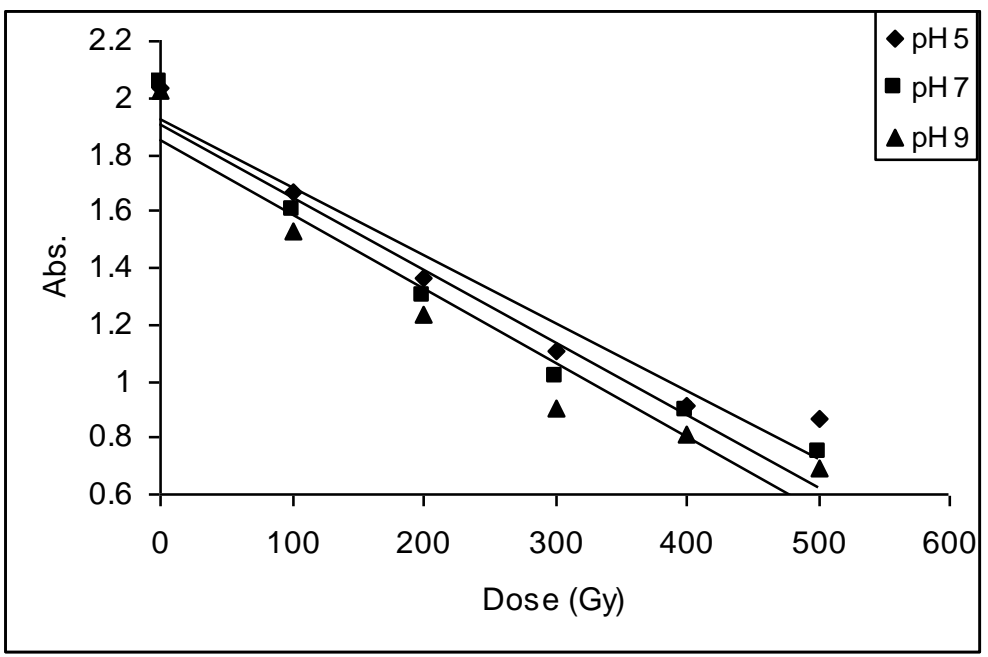

Figure 8: shows that Tartarzine of concentration $10^{-3} \mathrm{M}$ is more bleached after 24 hours of primary irradiation especially at $\mathrm{pH} 9$ 


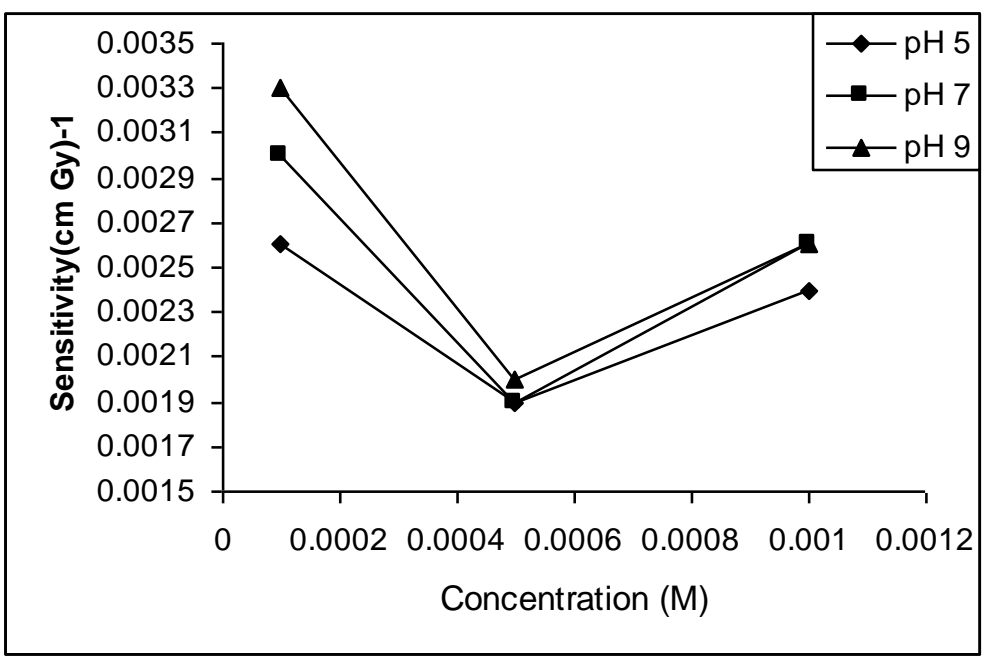

Figure 9: Dependence of sensitivity on the concentration of Tartarzine solution.

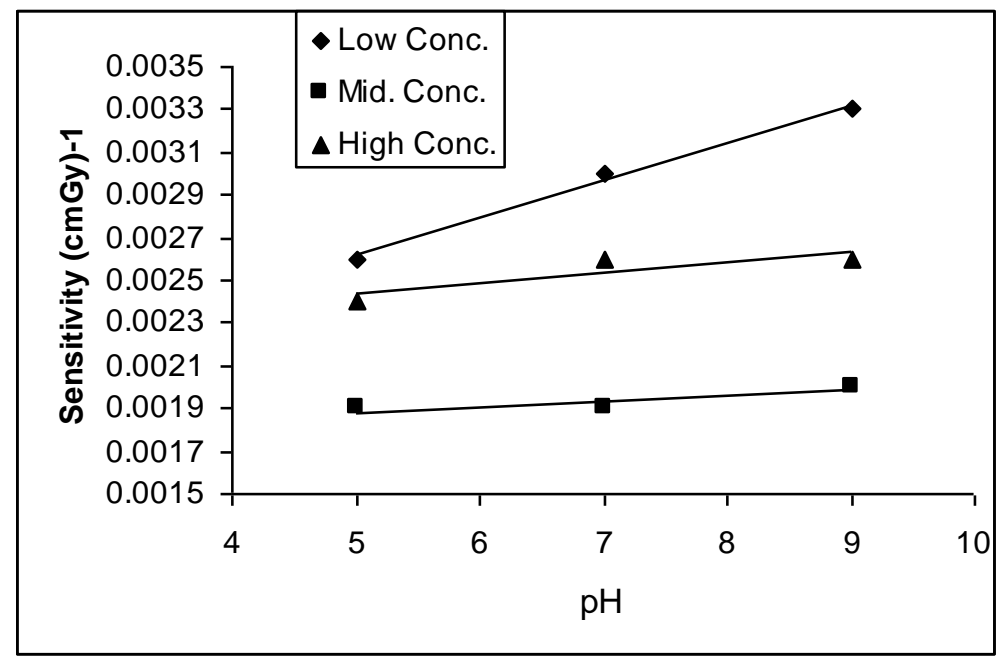

Figure 10: Dependence of sensitivity on the $\mathrm{pH}$ value of Tartarzine solution. 
Table 1: Linear equations represent the linear absorbance response to dose for different initial concentrations and $\mathrm{pH}$ values.

\begin{tabular}{|c|c|c|c|c|c|}
\hline \multirow{2}{*}{$\begin{array}{c}\text { Initial } \\
\text { concentration } \\
(\mathrm{M})\end{array}$} & \multirow{2}{*}{$\begin{array}{c}\text { Initial } \\
\mathrm{pH}\end{array}$} & \multicolumn{2}{|c|}{ Directly after irradiation } & \multicolumn{2}{c|}{ Post irradiation, 24 hours } \\
\cline { 2 - 6 } & & Linear equation & $r^{2}$ & Linear equation $^{*}$ & $r^{2}$ \\
\hline \multirow{3}{*}{$10^{-4}$} & 5 & $\mathrm{y}=-0.0025 \mathrm{x}+0.7946$ & 0.9886 & $\mathrm{y}=-0.0026 \mathrm{x}+0.7812$ & 0.9928 \\
\cline { 2 - 6 } & 7 & $\mathrm{y}=-0.0028 \mathrm{x}+0.7913$ & 0.9890 & $\mathrm{y}=-0.0030 \mathrm{x}+0.7863$ & 0.9863 \\
\cline { 2 - 6 } & 9 & $\mathrm{y}=-0.0031 \mathrm{x}+0.7894$ & 0.9859 & $\mathrm{y}=-0.0033 \mathrm{x}+0.7746$ & 0.9763 \\
\hline \multirow{3}{*}{$5 \times 10^{-4}$} & 5 & $\mathrm{y}=-0.0018 \mathrm{x}+1.3462$ & 0.9815 & $\mathrm{y}=-0.0019 \mathrm{x}+1.3257$ & 0.9742 \\
\cline { 2 - 6 } & 7 & $\mathrm{y}=-0.0018 \mathrm{x}+1.3104$ & 0.9588 & $\mathrm{y}=-0.0019 \mathrm{x}+1.2733$ & 0.9527 \\
\cline { 2 - 6 } & 9 & $\mathrm{y}=-0.0018 \mathrm{x}+1.2627$ & 0.9576 & $\mathrm{y}=-0.0020 \mathrm{x}+1.2402$ & 0.9561 \\
\hline \multirow{3}{*}{$10^{-3}$} & 5 & $\mathrm{y}=-0.0021 \mathrm{x}+1.9976$ & 0.9949 & $\mathrm{y}=-0.0024 \mathrm{x}+1.9249$ & 0.9747 \\
\cline { 2 - 6 } & 7 & $\mathrm{y}=-0.0023 \mathrm{x}+1.9678$ & 0.9909 & $\mathrm{y}=-0.0026 \mathrm{x}+1.9054$ & 0.9728 \\
\cline { 2 - 6 } & 9 & $\mathrm{y}=-0.0024 \mathrm{x}+1.9402$ & 0.9907 & $\mathrm{y}=-0.0026 \mathrm{x}+1.8521$ & 0.9635 \\
\hline
\end{tabular}

y represents Abs. and x represents dose (Gy).

Table 2: Percentages difference, PD\%, of Abs. between samples of "directly after irradiation" and "post irradiation, 24 hours".

\begin{tabular}{|c|c|c|c|c|c|c|c|c|c|c|}
\hline \multirow{3}{*}{$\begin{array}{c}\text { Initial } \\
\text { concentration } \\
(\mathrm{M})\end{array}$} & \multirow{3}{*}{$\begin{array}{c}\text { Initial } \\
\mathrm{pH}\end{array}$} & \multicolumn{9}{|c|}{$\mathrm{PD} \%$} \\
\hline & & 20 & 40 & 60 & 80 & 100 & 200 & 300 & 400 & 500 \\
\hline & & Gy & Gy & Gy & Gy & Gy & Gy & Gy & Gy & Gy \\
\hline \multirow{3}{*}{$10^{-4}$} & 5 & 2.5 & 3.3 & 2.2 & 5.5 & 0.2 & - & - & - & - \\
\hline & 7 & 1.2 & 2.4 & 2.4 & 3.7 & 2.6 & - & - & - & - \\
\hline & 9 & 3.7 & 4 & 3.8 & 0.5 & 3.7 & - & - & - & - \\
\hline \multirow{3}{*}{$5 \times 10^{-4}$} & 5 & - & - & - & - & 2.9 & 3.3 & 3.5 & 4.9 & 3.0 \\
\hline & 7 & - & - & - & - & 8.3 & 2.2 & 2.3 & 6.1 & 5.6 \\
\hline & 9 & - & - & - & - & 5.6 & 3.9 & 3.0 & 8.6 & 7.2 \\
\hline \multirow{3}{*}{$10^{-3}$} & 5 & - & - & - & - & 5.4 & 8.8 & 9.8 & 10.0 & 5.5 \\
\hline & 7 & - & - & - & - & 2.4 & 8.6 & 11.9 & 9.3 & 3.4 \\
\hline & 9 & - & - & - & - & 3.5 & 9.4 & 15.3 & 9.9 & 1.0 \\
\hline
\end{tabular}


Military Technical College

Kobry El-Kobbah, Cairo, Egypt

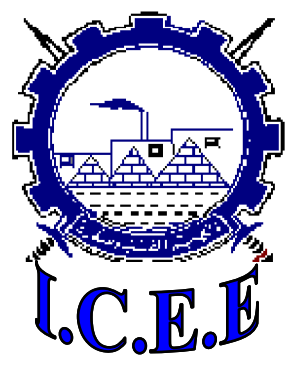

$5^{\text {th }}$ International Conference on

Chemical \& Environmental Engineering 25 - 27 May, 2010. 